\title{
A relação bacharelado- licenciatura e a natureza da prática pedagógica em artes
}

The relationship ba - bed and the nature of pedagogy in arts

Beatriz A. V. Cabral

Duas questões centrais permeiam os problemas curriculares na área de Ares e repercutem tanto nas metodologias quanto nos processos de avaliação: a relação BachareladoLicenciatura e a natureza das disciplinas ditas pedagógicas no curriculo. Estas questões se entrecruzam em diferentes instâncias, porém apresentam aspectos específicos.

Quando focalizamos as demais áreas de conhecimento e seus respectivos currículos podemos observar que a licenciatura representa uma complementação do bacharelado - após vivenciar o conteúdo específico, o aluno se especializa em seu ensino. Em Artes, entretanto, temos observado currículos diferenciados para o bacharelado e a licenciatura; estas em sua grande maioria inseridas em Cursos de Educação Artística, apresentam disciplinas com conteúdos específicos em grande parte descaracterizados, ou, na melhor das hipóteses, reduzidos e simplificados. Esta prática traz consequências muitas vezes desatrosas para o futuro professor; em teatro, por exemplo, este encontra-se muitas vezes despreparado para orientar um 
processo de montagem e/ou incapaz de diferenciar métodos de preparação/formação do profissional.

Os cursos de bacharelado, por sua vez, ao enfatizar a formação do artista, e ao manter uma confortável distância das deformações e simplificações desenvolvidas na área pedagógica, acabaram por afastar-se da reflexão sobre o 'fazer artístico' e sua estrutura conceitual.

Assim em ambas as áreas, bacharelado e licenciatura, pudemos observar um desenvolvimento dicotômico entre produto $\mathrm{x}$ processo, forma $x$ conteúdo. Se na área do bacharelado isto levou ao egocentrismo e ao distanciamento do espectador não iniciado, na área da licenciatura chegou-se ao absurdo de abandonar as áreas específicas de formação e estudos. Em geral, constatamos uma diminuição qualitativa dos saberes referentes à educação e à arte.

As reivindicações atuais de "identificar a área por Arte (e não mais por Educação Artística) e de incluí-la na estrutura curricular como área com conteúdos próprios ligados à cultura artística e não apenas como atividade educativa" trazem a necessidade de se repensar o 'pedagógico'- tanto em termos de teoria do conhecimento quanto no das metodologias para a formação do artista.

Mudar a imagem do 'pedagógico', entretanto, é um processo lento, que apresenta várias implicações que iniciam com, porém ultrapassam as, decisões curriculares - há que se pensar numa re-educação do corpo docente em termos teórico-práticos (uma série de seminários regionais, a exemplo das mudanças curriculares 
em outros países, por exemplo). Entre as mudanças de paradigma que apresentam as maiores dificuldades ou resistência estão as abordagens pedagógicas relacionadas com os conceitos de produção do conhecimento e educação das emoções.

Embora os conceitos de apropriação e produção do conhecimento e sua consequência imediata, o papel do professor como mediador na interação da criança com o contexto cultural que a cerca, sejam hoje praticamente consensuais em termos teóricos, a prática pedagógica, no 10, 20 e 30 graus, revela sérias contradições metodológicas. Podemos constatar com frequência, através dos estágios de observação dos alunos de licenciatura e mesmo através da prática de ensino destes, que a mediação é entendida no momento da oferta e investigação do material, mas a reprodução do conhecimento é cobrada no momento da interpretação e/ou avaliação do aluno. Observamos assim a lentidão e complexidade do processo de mudança de paradigma, e a oportunidade do alerta de Wittgenstein, para o qual, em vez do homem ser capaz de criar a linguagem, a língua e as artes criam o homem, pois as respostas e ações espontâneas, e as formas linguísticas e artísticas que se desenvolvem a partir delas dão ao homem sua concepção de mundo - uma concepção que é expressa não só sob a forma de palavras, mas principalmente em maneiras de vida e em possibilidades de ser.

Quanto à educação das emoções a confusão conceitual é grande - emoção e sensação tem sido tidas como sinônimo para efeitos metodológicos, gerando objetivos de ensino associados à sensorialização ou 
sensibilização e estratégias tais como os 'laboratórios de emoção'. Como resultado, professores se recusam a abordar questões emocionais ('não sou psicólogo', ouve-se constantemente), enquanto cursos extracurriculares oferecem o que é tido como 'concepção hidráulica' das emoções - estas surgem do nada ou de um estímulo sensorial, e 'jorram'independentemente das razões que as possam ter gerado. Neste caso, também é necessário e urgente considerar a reciclagem do professor ou seminários que promovam a revisão e análise conceitual dos aspectos subjacentes às mudanças de paradigma como prioridade equiparada à própria reforma curricular.

0 entendimento de que a emoção, em artes, envolvem a cognição e a compreensão do objeto desta emoção, nos remete a implicações metodológicas das quais dependem a possibilidade ou não da educação em, e através da, arte. Segundo David Best, não se trata aqui apenas de considerarmos sentimentos e cognição como inseparáveis, mas sim termos clareza de que a emoção em arte é cognitiva em si, evidenciando que as razões dadas para uma mudança de interpretação e avaliação são inseparáveis de uma mudança nos sentimentos envolvidos na situação/obra interpretada. Best exemplifica com Otelo, de Shakespeare, o qual ao considerar Desdemona uma mulher virtuosa, a idolatra e ama. É a cognição e o entendimento de sua virtude, a maneira pela qual ele a vê, que identifica ou determina seus sentimentos. Então lago lhe dá razões para um entendimento diverso - Desdemona é infiel e desonesta. Esta mudança de entendimento acarreta uma mudança de sentimentos (ciúme) e como resultado Otelo a mata. Tarde demais, Emília, 
mulher de lago, dá a Otelo razões para reconhecer a traição de lago e a inocência de Desdemona. Estas razões mudam sua concepção novamente, e com isto seu sentimento para o de um remorso intenso. Em cada situação o sentimento não foi separado da compreensão ou concepção do objeto deste sentimento Desdemona. Os sentimentos de Otelo, em cada caso, podem ser identificados somente em termos desta concepção.

0 espaço destinado às disciplinas pedagógicas no currículo de Artes apresenta um segundo foco de problemas. Mesmo com a ampliação da carga horária do curso de Artes Cênicas do Centro de Artes da UDESC para 4 anos e meio, o contato com as escolas de $10 \mathrm{e}$ 20 graus continuou restrito aos dois últimos semestres e totalmente desvinculado da maior parte das atividades do aluno no decorrer de sua formação. Disciplinas associadas à formação do professor como Psicologia e Sociologia da Educação e da Arte, Fundamentos da Arte na Educação, etc., ministradas nas primeiras fases, pouco acrescentaram à pratica de ensino nas últimas fases, uma vez que o espaço de tempo entre elas inviabilizou qualquer aproximação ou experiência intercurricular. Além disso, foi possível constatar que o equilíbrio, em número, entre disciplinas de formação do ator e disciplinas de formação do professor, em si não representa uma melhora de perspectiva significativa. É necessário que as duas áreas não se vejam como antagônicas, mas sim como complementares; que os professores da área pedagógica não reduzam nem simplifiquem a dimensão artística de seus objetivos e conteúdos; que os professores da área de 
formação do artista não descuidem ou ignorem o potencial pedagógico de suas atividades.

Uma nova re-estruturação curricular em 1994, com ampliação de carga horária das disciplinas pedagógicas, introdução de atividades programadas (8 créditos/120 horas, com possibilidade de serem distribuídas ao longo do curso), e monografia de final de curso, possibilitou um maior contato do aluno com a escola de primeiro grau e a comunidade, devido à necessidade de participar de projetos extracurriculares que contassem como atividades programadas e de realizar pesquisa ou experiências para subsidiar o trabalho de conclusão de curso. Estas medidas, entretanto, são ainda insuficientes para preparar e envolver o aluno com o ensino fundamental ou o trabalho em comunidade - pesquisa que desenvolvo atualmente mostra que menos de $20 \%$ de nossos ex-alunos estão envolvidos nestas atividades.

A dinâmica social brasileira e nossos problemas de educação e ensino, afastam o aluno da profissão, pois a universidade não o tem preparado para enfrentar esta realidade; a teoria tem se mostrado muito aquém, e usualmente impotente, para enfrentar os graves problemas do ensino básico público, como violência, drogas, e mesmo prostituição. Para enfrentá-los ou pelo menos se tentar formas de enfrentamento, é urgente uma maior interação universidade-comunidade-escola, durante todas as fases da licenciatura, e eu diria, também do bacharelado. O foco deve ser não a ampliação de disciplinas (a fragmentação já é excessiva), mas o tempo que o aluno tem para experiências na comunidade ou na escola de 10 grau, com acompanhamento da universidade e 
possibilidade de reflexão teórica concomitante durante toda a sua formação.

Uma distribuição equilibrada da carga horária do aluno entre trabalhos dentro e fora da universidade é importante tanto para os cursos de licenciatura, quanto para os cursos de bacharelado (aqui como artistas visitantes nas escolas de 10 grau, participantes de exposições, instalações, etc, nos centros comunitários, parques, etc.).

Este trabalho extra-curricular vem acontecendo em escala mínima, através dos programas de pesquisa e extensão, com o auxílio de bolsistas e fundos de apoio. Uma forma de ampliar estas iniciativas isoladas (poucos professores se dispõe a isso) seria descobrir formas de tornar esta prática uma exigência curricular - priorizando os trabalhos de estágio e relacionando-os com todas as disciplinas. Para cada teoria uma prática correspondente, quer através de projetos especiais, quer através de estágios supervisionados. As metodologias teriam assim que se adaptar a necessidades e especificidades práticas e os alunos seriam melhor preparados para se situar profissionalmente.

Algumas iniciativas neste sentido apontaram para problemas diretamente relacionados com o currículo e/ou política educacional brasileira:

1. a tentativa de privilegiar um estágio de observação já na primeira fase, como tarefa de pesquisa da disciplina Fundamentos da Arte na Educação, foi prejudicada tanto pela grande fragmentação do currículo $(7$ disciplinas por fase, bibliografia e tarefas diversas e concomitantes), quanto pelo fato de que um 
grande número de alunos trabalharem e7ou fazerem dois cursos universitários ao mesmo tempo, um pela manhã e outro à tarde, inviabilizando assim trabalhos de equipe, extensão e pesquisa.

2. A carga horária de cada disciplina, associada ao número de disciplinas e sua ocupação integral do semestre inviabilizam as experiências extracurriculares. A possibilidade de reservar tres semanas no decorrer de cada semestre para montagem de um projeto conjunto, cada grupo de alunos com um professor, tempo integral, preparando e executando uma proposta de trabalho que no decorrer da $3 a$ semana pudesse percorrer escolas ou centros comunitários, sendo este tempo computado como carga horária curricular, é uma possibilidade sendo discutida mas ainda sem soluções para operacionalização.

3. O problema da avaliação tem sido enfrentado de formas diversas, tais como 'conselhos pedagógicos', avaliação do professor pelos alunos, avaliação conjunta aluno-professor, avaliação através de questionários com retorno aos alunos e/ou aos professores, avaliação em grupo ou individual, etc., todas estas formas tendo apresentado episódios contraproducentes e constrangedores. A dificuldade, em meu entender, está na necessidade de se atribuir nota ou conceito ao desempenho do aluno por tarefa e disciplina em vez de se relacionar os conceitos a critérios a serem atingidos a médio ou longo prazo. A avaliação mensal, por tarefa, acaba levando à comparação e competição entre os alunos, em detrimento do preenchimento de critérios. Já a avaliação por trabalho concluído (através de etapas baseadas em 'suficiente', 'insuficiente') permitiria contemplar ritmos e métodos de trabalho diversos e avaliar cada 
aluno a medida que suas tarefas forem completadas, independentemente de datas e circunstâncias particulares. Neste sentido seria interessante começarmos a discutir o potencial de um examinador externo (de outra universidade ou departamento), o qual traria maior objetividade à avaliação, focalizando os resultados atingidos e liberando o professor para colocar-se como parceiro do aluno ( e não juiz) na busca por melhores resultados.

A busca de alternativas para ampliar o contato universidade-escola-comunidade, em Florianópolis, tem mostrado resultados positivos através de Programas de Intercâmbio, publicações relacionadas com os trabalhos apresentados nas Semanas de Pesquisa e Extensão, Mostra de Teatro Educação, Festival de Inverno. Todas estas iniciativas implicam em concretização dos resultados alcançados e contato com público externo à universidade, o que é sintomático.

Um projeto de intercâmbio com a Universidade de Exeter (Inglaterra) patrocinado pela CAPES/British Council, propondo observadores externos para diferentes tipos de prática, a partir de pesquisa conjunta e publicação anual dos resultados obtidos, motivou alunos, professores e escolas públicas envolvidos na pesquisa. O engajamento do corpo discente com a pesquisa, independentemente da obtenção de bolsas ou outras formas de apoio, foi significativo a partir da aceitação do projeto - indicações de melhor desempenho antecipanram-se às missões do intercâmbio, o que evidencia a relevância de programas desta natureza. 
A publicação de anais com resumos dos projetos apresentados nas Semanas de Pesquisa e Extensão ampliaram não só a quantidade como também a qualidade dos trabalhos apresentados.

A I Mostra de Teatro Educação, realização em parceria Universidade Estadual (Udesc) e Federal (Ufsc) de Santa Catarina reuniu 8 grupos teatrais infantis para apresentações, oficinas e seminários. Pela manhã, os atores infantis participaram de oficinas ministradas pelos professores do Centro de Artes (cada oficina contando com representantes dos diferentes elencos), enquanto seus professores e diretores participaram de seminários que contaram com professores convidados. À tarde os grupos se apresentaram e foram envolvidos em debates com o público. Esta primeira versão da Mostra garantiu a continuidade dos grupos e novas montagens face à perspectiva de sua repetição em outubro de 97.

O Festival de Inverno do Ceart/Udesc apresenta espetáculos teatrais, musicais e exposições, resultantes dos trabalhos discentes naquele semestre, para a comunidade. Este evento acaba por agilizar o primeiro semestre como um todo e energisa os alunos para o retorno no segundo semestre.

Estes eventos, no entanto, exigem verba e disponibilidade de carga horária, e sua manutenção nem sempre é possível. Daí a necessidade de iscutí-los e garantir um canal específico para a viabilização de tais projetos. 


\section{Referências bibliográficas}

BEST, David. The Rationality of Feeling.

Londres, The Falmer Press, 1992.

GIPPS, Caroline. Developing Assessment for the National Curriculum. Londres, The Bedford Way Series, 1992.

HAYDON, Graham. Education and Values. Londres, Institute of Education, 1987.

SOMERS, John (Ed.) Reseach in Drama

Education. Vol. 1, Nos 1 e 2, Vol. 2, N.1. Oxford, Carfax, 1996 e 1997.

TAYLOR, Philip (Ed.) Researching Drama and Arts Education - Paradigms \& Possibilities. Londres, The Falmer Press, 1996. . NADIE Journal - International Research

Issue. Australia, Vol. 18, N.2, 1994. 